УДК 622.276 .43

\title{
ОСОБЕННОСТИ ВЫРАБОТКИ ТРУДНОИЗВЛЕКАЕМЫХ ЗАПАСОВ НЕФТИ НЕОДНОРОДНЫХ КОЛЛЕКТОРОВ ТЮМЕНСКОЙ СВИТЫ (НА ПРИМЕРЕ МЕСТОРОЖДЕНИЙ ООО «ЛУКОЙЛ-ЗАПАДНАЯ СИБИРЬ»)
}

\author{
Грачев Сергей Иванович1, \\ grachevsi@tyuiu.ru
}

\author{
Юдчиц Виталий Викторович², \\ YudchitsVV@tmn.lukoil.com
}

Дручин Виталий Сергеевич2, DruchinVS@tmn.lukoil.com

\author{
Юнусов Радмир Руфович 3 , \\ Radmir.Unusov@lukoil.com \\ 1 Тюменский индустриальный университет, \\ Россия, 625000, г. Тюмень, ул. Мельникайте, 70. \\ 2 Филиал ООО «ЛУКОЙЛ-Инжиниринг» «КогалымНИПИнефть» в г. Тюмени, \\ Россия, 625000, г. Тюмень, ул. Республики, 41. \\ з ООО «ЛУКОЙЛ-Западная Сибирь», \\ Россия, 628486, г. Когалым, ул. Прибалтийская 20.
}

\begin{abstract}
Актуальность. Из 26 промышленно-разрабатываемых месторождений 000 «ЛУКОЙЛ-Западная Сибирь» в Шаимском нефртегазоносном районе пласты средней юры продуктивны на 21 месторождении. В них сосредоточено 56 \% извлекаемых запасов нефтти. Залежи отложений средней юры имеют сложное геологическое строение и характеризуются неоднородностью по разрезу, не выдержаны по простиранию, имеют в целом низкие фильтрационно-емкостные свойства. Запасы нефти в отложениях пластов тюменской свиты отнесены к трудноизвлекаемым по стратиграфической принадлежности. Отбор нефти в них от начальных извлекаемых запасов по состоянию на 01.01 .2021 2. составляет всего 8,6 \%. Темп отбора от НИз 0,4 \% в год. Исследование особенностей выработки коллекторов тюменской свиты является актуальной задачей.

Цель: выявить ключевые геолого-фризические особенности разработки коллекторов тюменской свиты для поиска методов и технологий повышения эфрфективности их разработки.

Объекты: коллекторы тюменской свиты Шаимского района.

Методы: контент-анализ, анализ и обобщение имеющегося опыта разработки коллекторов тюменской свиты на примере трех месторождений ООО «ЛУКОЙЛ-Западная Сибирь».

Результаты. Обобщены особенности геологического строения, выработки запасов пластов тюменской свиты и основные направления совершенствования технологии разработки. По результатам проведенного анализа выработки коллекторов тюменской свиты выявлены существеннье различия в эфффективности выработки запасов нефрти. По результатам интерпретации гидродинамических исследований, проведенных на рассматриваемых месторождениях, на двух выявлены коллекторы с двойной средой, что может оказывать существенное влияние на достижение различной эфрфективности разработки указанных месторождений. Во многом низкая эффективность разработки объектов тюменской свиты обусловлена применяемыми системами разработки, запроектированными на недостаточно геологически изученных залежах. Важной прикладной задачей эксплуатации порово-трещиноватого коллектора является определение величины дренируемых запасов и возможность прогнозирования их выработки с применением характеристик вытеснения, соответствующих типу продуктивного пласта.
\end{abstract}

\section{Ключевые слова:}

Тюменская свита, низкопродуктивные коллекторы, двойная среда, порово-трещиноватый коллектор, особенности разработки, гидродинамические исследования, заводнение.

Из 26 промышленно-разрабатываемых месторождений ООО «ЛУКОЙЛ-Западная Сибирь» в Шаимском нефтегазоносном районе пласты средней юры продуктивны на 21 месторождении. В них сосредоточено $56 \%$ извлекаемых запасов нефти. Залежи отложений средней юры имеют сложное геологическое строение и характеризуются неоднородностью по разрезу, не выдержаны по простиранию, имеют в целом низкие фильтрационно-емкостные свойства [1]. Запасы нефти в отложениях пластов тюменской свиты отнесены к трудноизвлекаемым по стратиграфиче- ской принадлежности. Отбор нефти в них от начальных извлекаемых запасов по состоянию на 01.01 .2021 г. составляет всего 8,6 \%. Темп отбора от НИЗ $0,4 \%$ в год.

На месторождениях Шаимского нефтегазоносного района деятельности «ЛУКОЙЛ-Западная Сибирь» промышленная нефтеносность установлена в доюрском складчатом фундаменте (кора выветривания КВ), в среднеюрских (пласты Т, Ю2-9), верхнеюрских отложениях (пласт П, Ю ${ }_{0}$ и викуловской свите. Месторождения, описываемые в работе, многопластовые, 
расположены в западной (месторождение 1), центральной (месторождение 2) и восточной частях (месторождение 3) района.

На месторождении 1 терригенные отложения тюменской свиты, представленные нефтенасыщенными коллекторами, имеют повсеместное распространение. Продуктивные отложения пласта П присутствуют лишь в пределах центральной части месторождения, а нефтенасыщенные коллекторы коры выветривания распространены в центральной и западной частях, имея мозаичный характер распространения.

На месторождении 2 продуктивными являются только три пласта тюменской свиты. Выше и ниже по разрезу нефтенасыщенных отложений не выявлено.

На месторождении 3 основные запасы нефти приурочены к отложениям викуловской свиты, в которой наибольшие перспективы связаны с областью врезанной долины. В центральной части месторождения открыты локальные залежи в нормальном разрезе баженовской свиты, в южной части продуктивна кора выветривания. Отложения тюменской свиты продуктивны на всей площади месторождения. Этаж нефтеносности тюменских отложений превышает 110 м.

Разработка изучаемых месторождений началась более 30 лет назад. Для вовлечения запасов нефти в

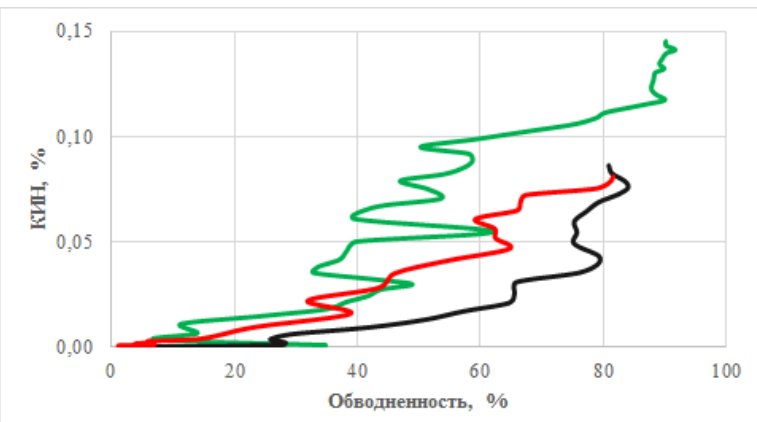

- Месторождение 1 - Месторождение 2 - Месторождение

Рис. 1. Показатели разработки по трем месторождениям

Fig. 1. Development parameters of three fields

В связи с низкой продуктивностью весь фонд добывающих скважин эксплуатируется механизированным способом, средний дебит жидкости для месторождения $1 \sim 51,7$ т/сут, дебит нефти 5 т/сут (рис. 2, a); для месторождения $2 \sim 26,1 \mathrm{~T} /$ сут, дебит нефти 4,1 т/сут (рис. 3,a); для месторождения $3 \sim 26,6$ т/сут, дебит нефти 3,7 т/сут (рис. 4, a). Часть добывающих скважин месторождений, имеющих низкие дебиты нефти и высокую обводненность, выведена в консервацию. Потенциал неработающего фонда скважин трех месторождений низкий - до 2 т/сут по нефти (рис. 2, б; 3, б; 4, б). Механизированный фонд скважин эксплуатируется при динамических уровнях 700-800 м и забойных давлениях, которые обычно превышают проектные значения на 2-3 МПа, коэффициент эксплуатации механизированного фонда скважин составляет $0,6-0,7$.

В пласты с начала разработки ведется закачка воды, для изучаемых месторождений отбор жидкости разработку в проектно-технологических документах рекомендуется применение плотных сеток скважин, избирательное заводнение и методы интенсификации добычи. На первом этапе были введены в разработку продуктивные пласты и участки, имеющие лучшие коллекторские свойства. Отложения тюменской свиты разбурены по рядной системе. Залежи эксплуатировались одиночными скважинами. Пробуренные до 2021 г. скважины сформировали на месторождениях очагово-избирательную систему заводнения с плотностью сетки 16 га/скв. Выявлено существенное различие в эффективности выработки запасов нефти на месторождениях (рис. 1).

Разбуривание месторождений не завершено, фонд скважин составляет от $22 \%$ (месторождение 3 ) до $77 \%$ (месторождение 1) от проектного фонда.

За период разработки месторождений выполнен большой объем гидродинамических исследований скважин (охват скважин исследованиями - более 50 \%), в результате которых установлен диапазон значений коэффициента продуктивности 0,1-15,4 м $^{3} /$ сут:МПа (среднее значение $3,6 \mathrm{~m}^{3} /$ сут МПа). Повторные замеры показали, что в результате обводнения продуктивность снижается в три раза. Скин-фактор по пластам имеет отрицательное значение (в среднем 1,5).

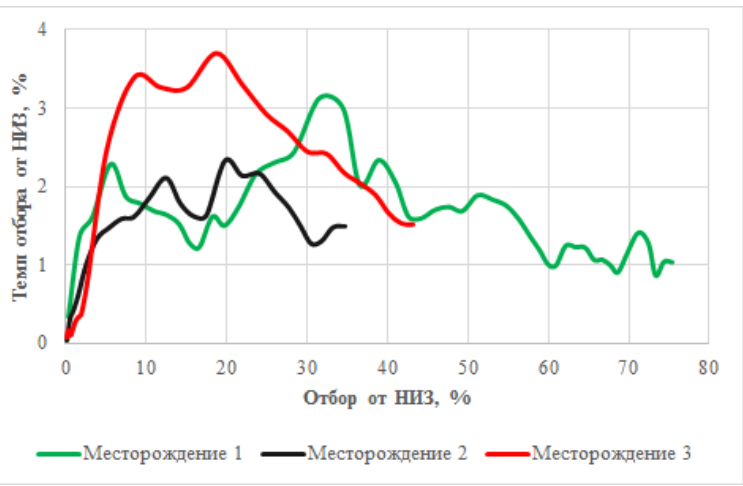

компенсирован на 90-130 \%. В результате текущее пластовое давление в зонах отбора по площади месторождений среднем на 0,3-0,6 МПа выше первоначального.

В 2015-2020 гг. на месторождениях велось бурение уплотняющих скважин. Стоит отметить, что зачастую бурение велось на участках, где имелся длительный период эксплуатации и была вероятность влияния разработки. На анализируемых участках пробуренные до 2015 г. скважины работали с текущей обводненностью от 45 до $99 \%$, из них в $65 \%$ скважин обводненность превышала 72 \%. В таких сложных условиях только четыре из девятнадцати скважин уплотняющего фонда, пробуренные между рядами нагнетательных и добывающих скважин, вскрыли промытые нефтенасыщенные коллекторы и вступили в эксплуатацию с обводненностью более 45 \% соответственно. Остальные 15 скважин дали практически безводную нефть. 


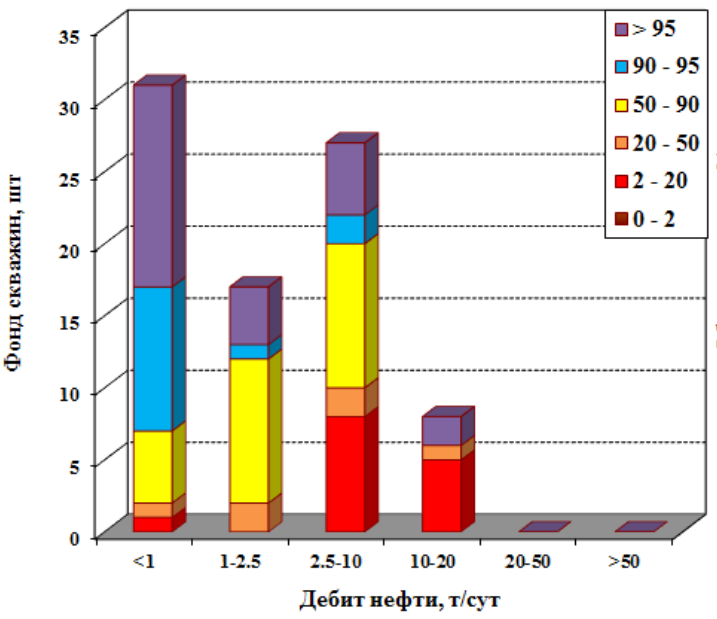

$a / a$

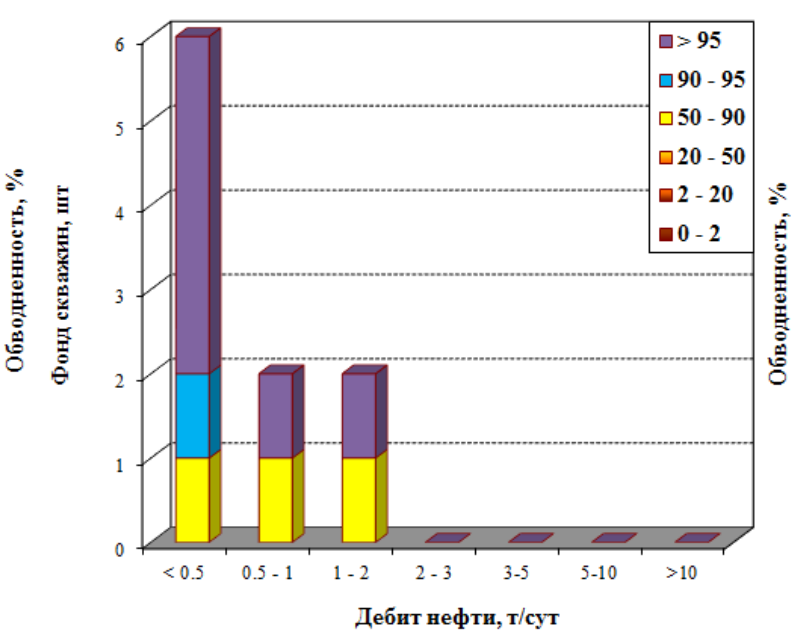

$6 / b$

Pис. 2. Распределение (а) действующего фонда скважин и (б) неработающего фонда скважин, по дебитам нефти месторождения 1

Fig. 2. Distribution of (a) active wells and (b) idle wells, based on oil production rate of field no. 1

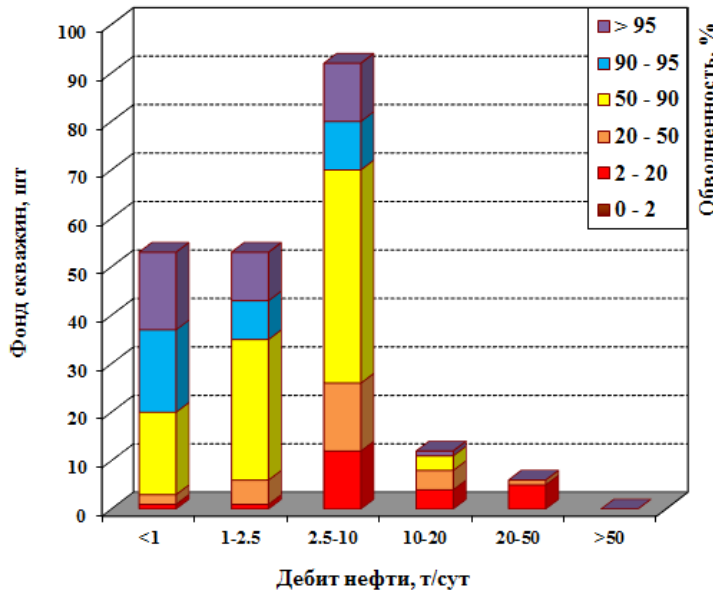

$a / a$

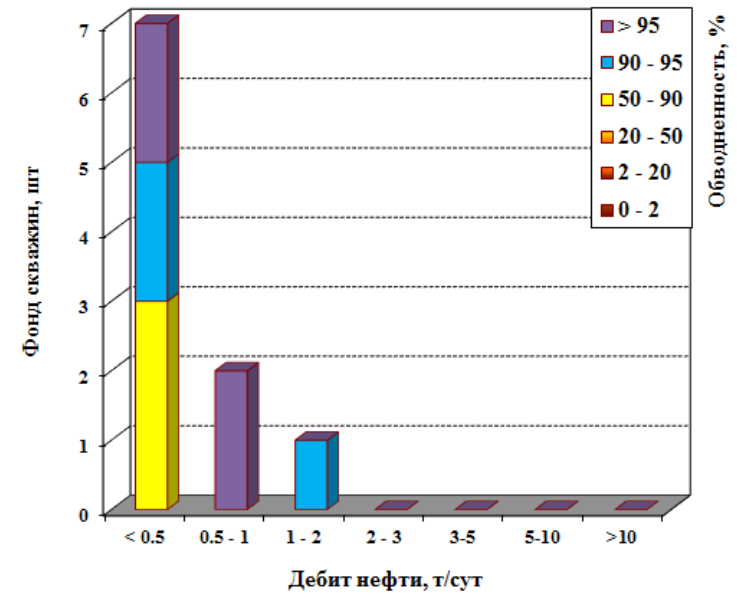

$\sigma / b$

Pис. 3. Распределение (а) действующего фонда скважин и (б) неработающего фонда скважин, по дебитам нефти месторождения 2

Fig. 3. Distribution of (a) active wells and (b) idle wells, based on oil production rate of field no. 2
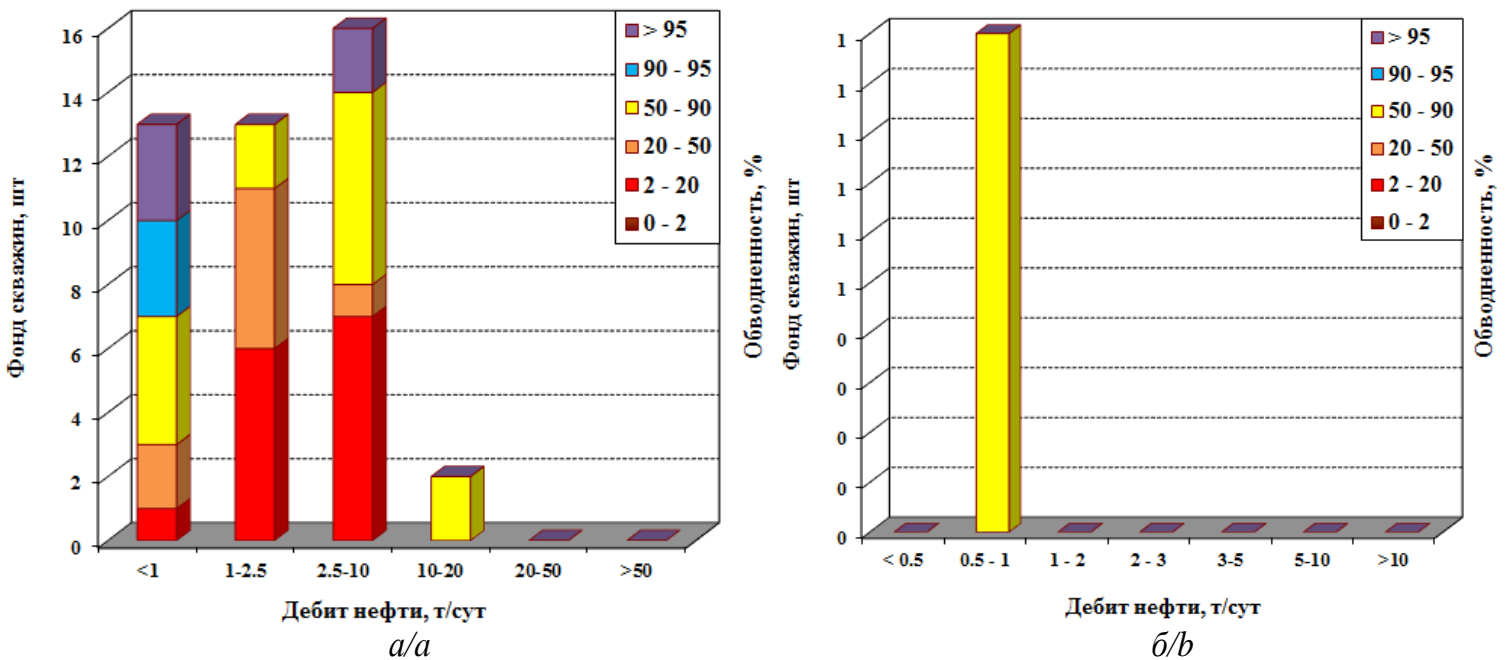

Pис. 4. Распределение (а) действующего фонда скважин и (б) неработающего фонда скважин, по дебитам нефти месторождения 3

Fig. 4. Distribution of (a) active wells and (b) idle wells, based on oil production rate of field no. 3 
Средняя накопленная добыча нефти на одну уплотняющую скважину составила 16,7 тыс. т, изменяясь от 3,0 до 90,9 тыс. т. По результатам геологогидродинамического моделирования проведен анализ плотности остаточных запасов нефти в изучаемых отложениях и предложены дополнительные мероприятия по технологиям разработки месторождений:

- увеличение числа нагнетательных скважин за счет перевода низкодебитных добывающих скважин для организации избирательной закачки в интервалы пласта, не охваченные воздействием;

- уплотняющее бурение в выявленные на гидродинамической модели зоны с повышенной плотностью запасов;

- ввод из бездействия добывающих и нагнетательных скважин;

- повышение нефтеотдачи пластов за счет воздействия на пласт составами, обеспечивающими изоляцию промытых зон коллекторов.

Уплотняющие скважины на месторождениях 1 и 2 вскрыли часть нефтенасыщенного коллектора, отсутствующего в разрезах окружающих добывающих и нагнетательных скважин, тем самым подтвердив высокую степень прерывистости нефтенасыщенных коллекторов по простиранию.

Продуктивные отложения тюменской свиты на всех изучаемых месторождениях имеют достаточно большую общую толщину, которая изменяется от 0 м в зонах выклинивания до 180 м в наиболее погруженных зонах и разделяется глинисто-алевритистыми пе- ремычками на 10-18 и более песчаных прослоев. В пределах границ горизонта выделяется от двух до семи примерно равных по толщине продуктивных пластов. Основные геологические особенности отложений тюменской свиты представлены в работах [2-4].

Развитие песчаных тел в разрезе носит сложный характер. Наряду с наличием множества изолированных песчаных линз, вскрытых единичными скважинами, по результатам специализированных работ по интерпретации сейсмических материалов в пределах месторождения 3 выявлены выдержанные по площади песчаные тела - «палеорусла», протяженность которых составляет от 1,6 до 5 км. Аналогичные зоны выявлены по скважинным данным на месторождениях 1 и 2.

Коллекторами являются песчаники нефтенасыщенные и алевролиты плотные, глинистые. Песчаники в основном кварц-полевошпатовые, мелкозернистые, слоистые за счет включений углисто-глинистых разностей, слюдистые. Из глинистых минералов преобладает каолинит. В составе песчаников встречаются карбонатные минералы, однако в отличие от пласта П содержание карбонатов в тюменских песчаниках значительно ниже (в среднем 2-3\%).

Основная часть коллекторов (94 \%), выделенных по результатам интерпретации геофизических исследований скважин (ГИС), сложена пропластками толщиной до 1,5 м, в том числе $35 \%$ нефтенасыщенных пропластков имеют толщину до 0,6 м, 32 - от 0,6 до 1,0 м (табл. 1).

Таблица 1. Статистическое распределение нефтенасыщенных прослоев отложений тюменской свиты по толщиHaм

Table 1. Statistical distribution of oil bearing layers in Tyumen geological interval based on their thickness

\begin{tabular}{|c|c|c|c|c|c|c|c|c|c|}
\hline \multirow{2}{*}{ Месторождение/Field } & \multicolumn{9}{|c|}{ Интервал толщин, м/Thickness, $\mathrm{m}$} \\
\cline { 2 - 11 } & $0-0,6$ & $0,6-1$ & $1-2$ & $2-3$ & $3-4$ & $4-5$ & $5-6$ & $6-7$ & болеe 7/more than 7 \\
\hline 1 & 48,3 & 28,7 & 17,2 & 3,3 & 1,6 & 0,5 & 0,2 & 0,2 & 0,1 \\
\hline 2 & 36,7 & 30,8 & 26,1 & 5,0 & 0,9 & 0,2 & 0,1 & 0,1 & - \\
\hline 3 & 26,1 & 39,7 & 27,8 & 5,7 & 0,4 & 0,3 & 0,1 & - & - \\
\hline
\end{tabular}

Установленное наличие в разрезе пласта нефтенасыщенных пропластков толщиной до двух метров с плохой выдержанностью по простиранию подтверждает прерывистое строение, определяющее низкую величину песчанистости пластов. Песчанистость пластов тюменской свиты месторождения 1 равна 0,2 , месторождения 2 - 0,18, месторождения 3 - 0,09. Расчлененность пласта Т1 изменяется от 1 до 9, в среднем составляя 3,3. На месторождении 3 семь продук- тивных пластов тюменской свиты были объединены в единый объект учета запасов, расчлененность равна 16 , для отдельных пластов расчлененность изменяется от 2 до 4.

Значения коэффициента проницаемости варьируют от $0,001 \cdot 10^{-3}$ до $173 \cdot 10^{-3}$ мкм $^{2}$. Для рассматриваемых месторождений $75 \%$ всех пропластков имеют проницаемость, не превышающую $10 \cdot 10^{-3}$ мкм $^{2}$ (табл. 2).

Таблица 2. Статистическое распределение нефтенасыщенных прослоев отложений тюменской свиты по прониизаемости (по ГИС)

Table 2. Statistical distribution of oil bearing layers in Tyumen geological interval based on their permeability (from logging data)

\begin{tabular}{|c|c|c|c|c|c|c|c|}
\hline \multirow[b]{2}{*}{ Месторождение/Field } & \multicolumn{7}{|c|}{ Интервал проницаемости, $* 10^{-3}$ мкм $^{2} /$ Permeability, $10^{-3} \mu \mathrm{m}^{2}$} \\
\hline & $\begin{array}{c}\text { менее } 1 \\
\text { less than } 1\end{array}$ & $1-2$ & $2-10$ & $10-20$ & $20-50$ & $50-100$ & $\begin{array}{c}\text { более } 100 \\
\text { more than } 100\end{array}$ \\
\hline 1 & 0,2 & 27,4 & 48,0 & 11,2 & 9,1 & 3,7 & 0,2 \\
\hline 2 & 34,7 & 14,5 & 25,6 & 7,8 & 7,7 & 3,7 & 6,0 \\
\hline 3 & 84,7 & 13,3 & 1,3 & 0,7 & - & - & - \\
\hline
\end{tabular}


С другой стороны, на месторождениях 1 и 2 скважинами вскрыты участки с улучшенными ФЕС: 12,8 и $11,4 \%$ пропластков имеют проницаемости более $20 \cdot 10^{-3}$ мкм² $^{2}$. На месторождении 3 коллекторы с проницаемостью более $10^{*} 10^{-3}$ мкм ${ }^{2}$ практически отсутствуют. В данном типе коллекторов фронтальное вытеснение нефти крайне затруднено, извлечение осуществляется преимущественно в режиме капиллярной пропитки в направлении естественных и техногенных трещин $[5,6]$.

Пористость пластов тюменской свиты колеблется от 11,5 до $21,3 \%$ и в среднем составляет для месторождений 1 и $218 \%$, а для месторождения $3-12 \%$. Толщина глинистой перемычки (неколлектора), разделяющей пласты тюменской свиты, изменяется от 0,8 до 22,8 м, средняя толщина $-7,0$ м.

Таким образом, выявлено, что отличительной особенностью пластов является наличие значительной доли пропластков коллектора толщиной менее $1 \mathrm{~m}$ (более $65 \%$ ). Среднее значение проницаемости коллектора не превышает $10 \cdot 10^{-3}$ мкм $^{2}$. Доля низкопроницаемого коллектора (менее $2 \cdot 10^{-3}$ мкм $^{2}$ ) составляет по месторождениям: 1 - 27,6\%, 2-49,2 \%, 3-98\%.

Анализ адаптации и настройки геологогидродинамической модели и промысловых данных показал, что коэффициенты действующих толщин (Кдт) по пачкам существенно отличаются и состав- ляют от 0,44 до 0,84 , что связано с различной песчанистостью пачек; наличием множества изолированных песчаных линз, не попадающих в зоны влияния нагнетания; появлением в скважинах прослоев коллекторов, имеющих аномально высокие фильтрационные свойства (проницаемость). Сделан вывод, что значения Кдт от 0,44 до 0,55 в объектах разработки связаны с высокой изменчивостью песчаных тел (фациальными границами) и отсутствием связи проницаемых прослоев в зоне добычи и нагнетания. Для участков гидродинамической модели с выдержанной литологией, характеризующихся высокой связанностью коллекторов, в добывающих скважинах значения Кдт превышают 0,7.

Для рассматриваемых в работе месторождений классическое гидродинамическое взаимодействие коллекторов между нагнетательными и добывающими скважинами по данным ПГИС подтверждено в $35 \%$ исследований. В $28 \%$ исследований вода от нагнетательных скважин при совместной эксплуатации нескольких пластов поступает в выше- и нижележащие пласты, коллекторы которых имеют повышенную проницаемость. В 18 \% случаев слабая гидродинамическая связь связана с зонами коллекторов с проницаемостью менее 2 мД и в $13 \%$ - взаимодействия прослоев коллекторов нет, т. к. в ближайшем окружении от добывающих скважин нет скважин с закачкой.

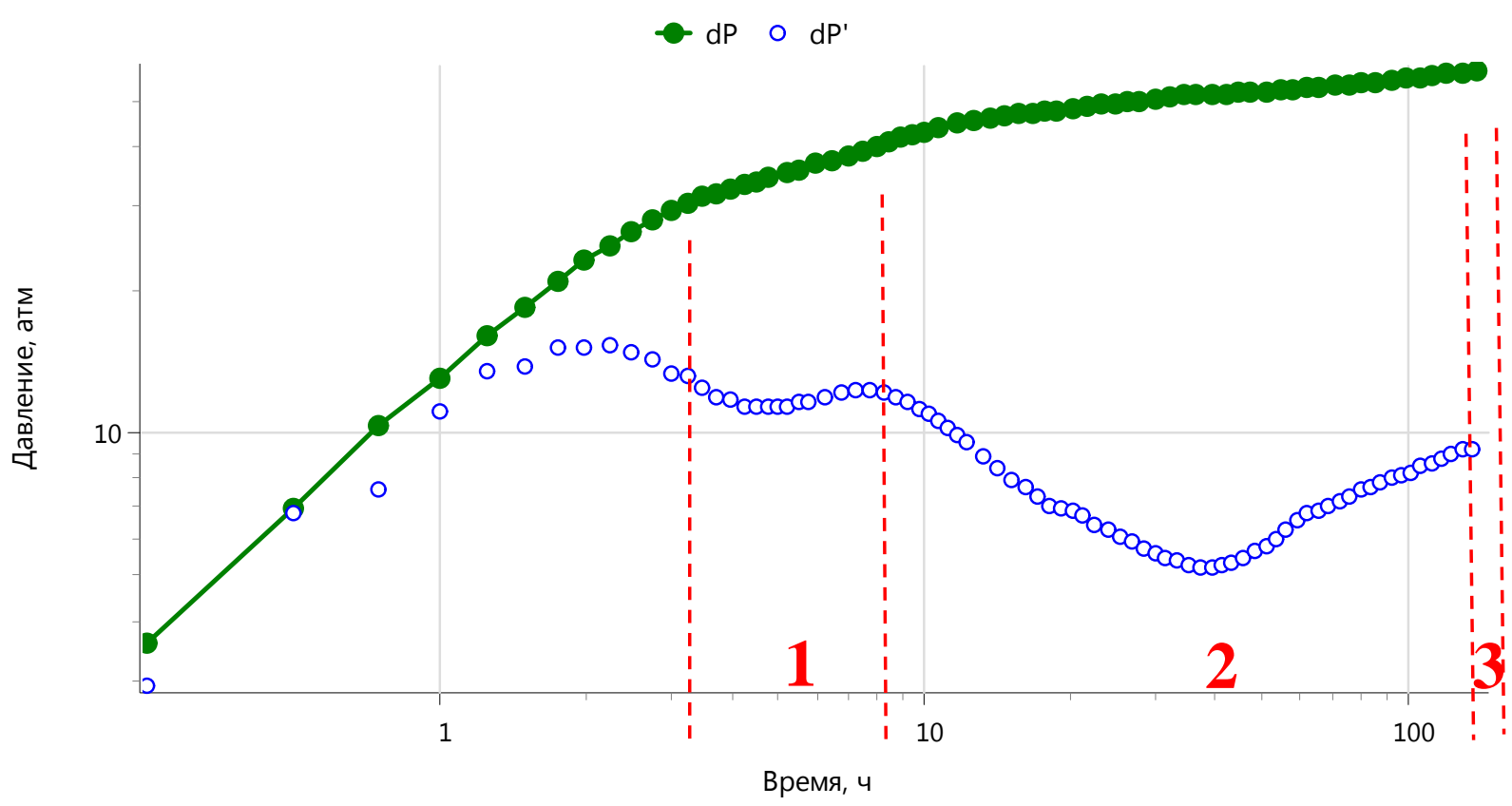

Pис. 5. Выделение коллектора с двойной проницаемостью по диагностическому графику КВД (месторождение 3)

Fig. 5. Identification of the reservoir with dual flow conditions based on pressure build-up graph (Field no. 3)

Проведено исследование важного фактора, который может влиять на достижения различной эффективности разработки указанных месторождений. При интерпретации результатов гидродинамических исследований (ГДИ) с применением ПО МГДИС выявлены коллекторы с двойной средой [7-9]. Распределение возмущенной части коллектора описывается моделью Баренблатта-Уоррена-Рута [10], при кото- рой фильтрацию флюида можно разделить на три периода (рис. 5):

1. Из-за того, что трещина имеет более высокою проницаемость, на раннем этапе исследования приток флюида осуществляется только через систему трещин. Характерно, что данный режим проявляется в течение короткого времени и часто не идентифицируется на графиках из-за эффекта сжимаемости жидкости в скважине. 
2. Далее следует переходный режим (матрицатрещина), который характеризуется скачком производной вниз и соответствует перераспределению давления между матрицей и системой трещин.

3. Вторая стабилизация производной соответствует радиальному притоку трещинно-матричной системы.

Проанализированы результаты более 250 исследований, и выявлено наличие двойной среды на 2 и 3 месторождениях (табл. 3).

Таблица 3. Результаты гидродинамических исследований Table 3. Results of hydrodynamic tests

\begin{tabular}{|c|c|c|c|c|}
\hline 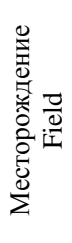 & 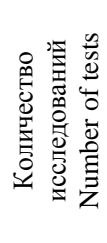 & 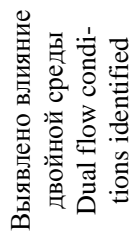 & 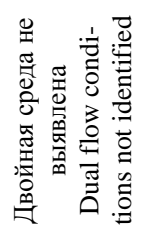 &  \\
\hline 1 & 81 & 0 & 60 & 21 \\
\hline 2 & 86 & $11(19 \%)$ & 46 & 29 \\
\hline 3 & 112 & $14(16 \%)$ & 75 & 23 \\
\hline
\end{tabular}

*недостаточное время замера/insufficient duration of test.

Характерные периоды фильтрации встречаются на 2 и 3 месторождениях и, соответственно, четко выделяются две зоны с различной проницаемостью (рис. 6-8). На рис. 8 видно отсутствие первого режима, что связано с низкой проницаемостью объекта и длительным эффектом влияния ствола в данной скважине.

Наличие двойной проницаемости подтверждено результатами лабораторных исследований ФЕС на керне. На месторождении 2 и 3 наблюдаются аномальные значения проницаемости образцов керна ( $3-5 \%$ определений), что указывает на наличие трещинной составляющей.

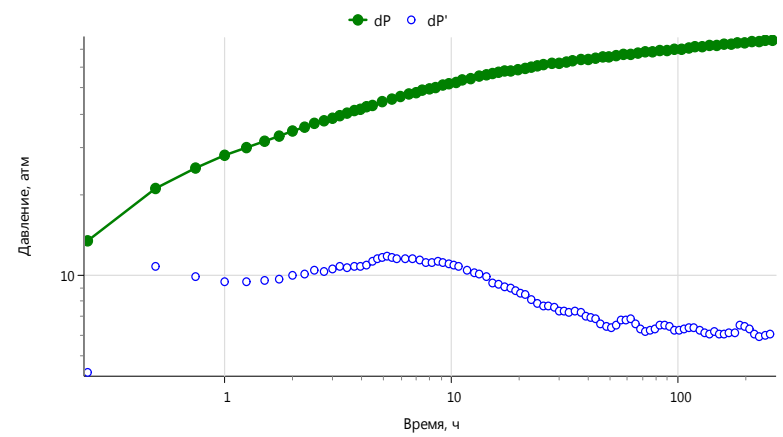

Pис. 6. Диагностический график КВД, характерный для скважин месторождения 1

Fig. 6. Typical pressure build-up graph for field no. 1 wells

Впервые описание процессов фильтрации поровотрещиноватых коллекторов и пластов с двойной средой выполнено Г.И. Баренблаттом и Ю.П. Желтовым. Из отечественных авторов, работы которых посвящены трещиноватости нефтяных месторождений Запад- ной Сибири, можно отметить Р.И. Медведского, К.С. Юсупова, В.А. Коротенко, А.А. Севастьянов, С.И. Грачева, среди зарубежных исследователей П. Полларда, П. Рута, Дж. Уоррена, М.М. Каземи [11].

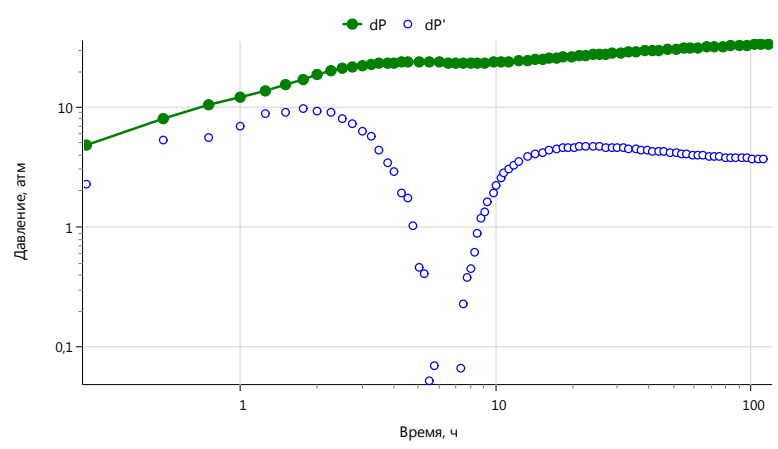

Pис. 7. Диагностический график КВД, характерный для коллектора с двойной средой на скважинах месторождения 2

Fig. 7. Typical pressure build-up graph for field no. 2 wells with dual flow conditions

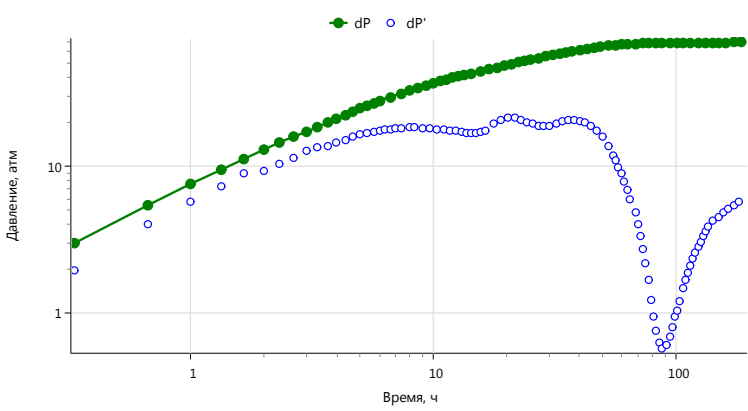

Pис. 8. Диагностический график КВД, характерный для коллектора с двойной средой на скважинах месторождения 3

Fig. 8. Typical pressure build-up graph for field no. 3 wells with dual flow conditions

Очевидно, что наличие коллекторов с двойной средой на месторождениях 2 и 3 отрицательно влияет на эффективность технологии заводнения: низкое значение текущего коэффициента извлечения нефти (менее $10 \%$ ); высокая обводненность добываемой продукции (более 80 \%). Это обусловлено тем, что лишь незначительная доля закачиваемой в пласт воды расходуется на вытеснение нефти, при том что основная доля нагнетаемой воды движется к добывающим скважинам по промытым каналам [12-14]. При этом установлено, что чем выше давление нагнетания, тем выше вероятность образования каналов высокой проводимости $[15,16]$. Результаты проведенного исследования соответствуют выводам в работе Р.И. Медведского и А.А. Севастьянова [17], что на месторождениях с трещиновато-поровыми коллекторами запланированная сетка скважин не позволяет выработать извлекаемые запасы в проектном объеме.

\section{Заключение}

По результатам анализа разработки залежей тюменской свиты Шаимского нефтегазоносного района необходимо отметить, что важной прикладной зада- 
чей эксплуатации порово-трещиноватого коллектора является определение величины дренируемых запасов и возможность прогнозирования их выработки с применением соответствующих типу продуктивного пласта характеристик вытеснения [18]. Анализ выработки запасов выявил влияние высокопроводящей среды на эффективность технологии заводнения на месторождениях 2 и 3.

Наиболее эффективной для эксплуатации коллекторов с двойной средой видится щадящая площадная система воздействия, которая позволит избежать опережающего обводнения продукции скважин. При этом особое внимание необходимо уделить текущей компенсации отборов. Так, на начальном этапе разработки текущая компенсация может превышать отборы жидкости с последующим сокращением закачки до уровня отборов нефти [19].

Также очевидным выводом является низкая эффективность разработки объектов тюменской свиты, представленных сложнопостроенными залежами с низкими ФЕС, неравномерным распределением участков низкопродуктивных коллекторов и остатков палеорусловых тел с относительно высокопродуктивным коллектором. Равномерные сетки эксплуатационных скважин, запроектированные на недостаточно

\section{СПИСОК ЛИТЕРАТУРЫ}

1. Трудноизвлекаемые запасы нефти Российской Федерации Структура, состояние, перспективы освоения: монография / И.В. Шпуров, А.Д. Писарницкий, И.П. Пуртова, А.И. Вариченко. - Тюмень: Министерство природных ресурсов и экологии Российской Федерации (Минприроды России), Федеральное агентство по недропользованию (Роснедра), ЗападноСибирский научно-исследовательский институт геологии и геофизики, ЗапСибНИИГГ, 2012. - 256 с.

2. Бембель С.Р. Особенности геологического строения горизонта $\mathrm{Ю}_{2}$ Западной Сибири на основе анализа сейсмических данных // Международный научно-исследовательский журнал «Norwegian Journal of development of the international science». - 2019. № 36. - C. 10-13.

3. Совершенствование системы разработки Сыморьяхского месторождения с использованием скважин сложной архитектуры / В.В. Юдчиц, Р.Е. Литовар, А.Ю. Сенцов, В.С. Дручин, Р.Р. Юнусов, М.В. Назаров // Геология, геофизика и разработка нефтяных и газовых месторождений. - 2020. - Т. 345. № 9. - С. 87-92.

4. Шпуров И.В., Захаренко В.А., Фурсов А.Я. Дифференцированный анализ степени вовлечения и выработанности запасов юрских залежей в пределах Западно-Сибирской НГП // Недропользование XXI век. - 2015. - Т. 51. - № 1. - С. 12-19.

5. Pressure transient analysis for multi-wing fractured wells in dualpermeability hydrocarbon reservoirs / Qi-guo Liu, You-jie Xu, Xian Peng, Yicheng Liu, Shengzhi Qi // Journal of Petroleum Science and Engineering. - 2019. - V. 180. - P. 278-288.

6. Грачев С.И., Черняев А.В., Шпуров И.В. Совершенствование разработки коллекторов Юрских отложений // Известия высших учебных заведений. Нефть и газ. - 2012. - № 4. - С. 53-57.

7. Особенности геологического строения и концептуальные геологические модели продуктивных пластов Кочевского месторождения, запасы которых оценены к категории трудноизвлекаемых / Н.Г. Аржиловская, Д.С. Баймухаметов, В.С. Дручин, П.В. Хлызов, М.Р. Мазитов // Актуальные проблемы нефтегазовой отрасли. Сборник докладов научно-практических конференций журнала «Нефтяное хозяйство». - М., 2019. - С. 108-117.

8. A new numerical well testing approach: application to characterization of complex fault structures / B. Pouladi, M. Sharifi, M.R. Akbari, S.M. HosseiniNasab // Petroleum. 2019. - V. 5. - Iss. 3. - P. 295-302. геологически изученных залежах, приводят к низкой эффективности разработки. Поэтому большинство эксплуатационных скважин расположено в зонах низкой продуктивности. И никакие дополнительные методы повышения нефтеотдачи, включая выполнение ГРП и бурение ГС, не способны перевести разработку подобных трудноизвлекаемых запасов (тюменской свиты) в категорию «эффективных» и окупаемых [20].

Сюда же следует отнести распределение в разрезе и территории залежей и месторождений участков с наличием трещинного и порово-трещинного коллектора, местоположение которого становится болееменее известным только по результатам эксплуатационного бурения, динамики работы добывающих и нагнетательных скважин, ПГИ.

Перечисленные особенности сложного распределения относительно высокопродуктивных коллекторов и низкопродуктивных участков (занимающих основную часть площади залежей) в отложениях тюменской свиты требуют, в первую очередь, постановки детальных геолого-геофизических исследований при прогнозе и картировании их фильтрационноемкостных характеристик на этапе подготовки к вводу в эксплуатацию и проектирования разработки таких месторождений.

9. Study on characteristics of well-test type curves for composite reservoir with sealing faults / Qiguo Liu, Heng Lu, Longxin Li, Aiting Mu // Petroleum. - 2018. - V. 4. - Iss. 3. - P. 309-317.

10. Warren J.E., Root P.J. The behavior of naturally fractured reservoirs // Society of Petroleum Engineers Journal. - 1963. V. September. - P. 245-255.

11. Numerical simulation of water-oil flow in naturally fractured reservoirs. / H. Kazemi, L.S. Merrill, K.L. Porterfield, P.R. Zeman // Society of Petroleum Engineers Journal. - 1976. - V. December. P. 317-326.

12. Grachev S.I., Korotenko V.A., Kushakova N.P. Study on influence of two-phase filtration transformation on formation of zones of undeveloped oil reserves // Journal of Mining Institute. - 2020. V. 241. - P. $68-82$.

13. Dual porosity and dual permeability modeling of horizontal well in naturally fractured reservoir / Nie Ren-Shi, Meng Ying-Feng, Jia Yong-Lu, Zhang Fu-Xiang, Yang Xiang-Tong, Niu Xin-Nian // Transport in Porous Media, - 2012. - V. 92. - P. 213-235.

14. Uleberg K., Kleppe J. Dual porosity, dual permeability formulation for fractured reservoir simulation // Trondheim RUTH Seminar. - Stavanger: Norwegian University of Science and Technology, 1996.

15. Афанасьев А.В., Горбунов А.Т., Шустеф И.Н. Заводнение нефтяных месторождений при высоких давлениях нагнетания. - М.: Изд-во «Недра», 1975. - 215 с.

16. Медведский Р.И. Концепция струйного вытеснения нефти водой // Вестник Удмуртского университета. - 2002. - № 9. C. $121-129$

17. Медведский Р.И., Севастьянов А.А. Сопоставление методов прогнозирования извлечения запасов нефти в слоистых пластах // Известия высших учебных заведений. Нефть и газ. 1998. - № 4. - C. 42-47.

18. Медведский Р.И., Севастьянов А.А. Использование обобщенной характеристики вытеснения при анализе разработки и прогнозировании выработки запасов // Пути реализации нефтегазового потенциала XMAO: Шестая научно-практическая конференция. - Ханты-Мансийск, 2003. - Т. 1. - С. 371-384.

19. Методическое обоснование повышения выработки запасов нефти месторождений, осложненных тектоническими нарушениями / А.В. Стенькин, Ю.А. Котенов, Ш.Х. Султанов, В.Г. Уметбаев // Известия Томского политехнического университета. Инжиниринг георесурсов. - 2019. - Т. 330. - № 1. C. 214-223 
20. Геологическая модель и обоснование оптимального размещения скважин на объектах тюменской свиты западной части Ханты-Мансийского автономного округа - Югры / С.Р. Бембель, Р.В. Авершин, Р.М. Бембель, В.И. Кислухин // Изве- стия высших учебных заведений. Нефть и газ. - 2020. - № 6. C. $8-24$.

Поступила 13.10.2021 2.

\section{Информация об авторах}

Грачев С.И., доктор технических наук, профессор, заведующий кафедрой разработки и эксплуатации нефтяных и газовых месторождений Тюменского индустриального университета.

Юдчиц В.В., начальник отдела проектирования и мониторинга разработки месторождения им. В.Н. Виноградова Филиала ООО «ЛУКОЙЛ-Инжиниринг» «КогалымНИПИнефть» в г. Тюмени.

Дручин В.С., кандидат геолого-минералогических наук, заместитель директора Филиала ООО «ЛУКОЙЛИнжиниринг» «КогалымНИПИнефть» в г. Тюмени по научной работе в области геологии.

Юнусов Р.P., начальник отдела контроля и анализа разработки месторождений нефти и газа ООО «ЛУКОЙЛЗападная Сибирь». 
UDC 622.276 .43

\title{
SPECIFIC ASPECTS OF OIL RESERVES DEVELOPMENT FROM DISCONTINUOUS LOW-PRODUCTIVE RESERVOIRS OF TYUMEN GEOLOGICAL INTERVAL (ON THE EXAMPLE OF JSC LUKOIL-WEST SIBERIA FIELDS)
}

\author{
Sergey I. Grachev1, \\ grachevsi@tyuiu.ru \\ Vitaly V. Yudchits'2, \\ YudchitsVV@tmn.lukoil.com \\ Vitaly S. Druchin², \\ DruchinVS@tmn.lukoil.com \\ Radmir R. Yunusov ${ }^{3}$, \\ Radmir.Unusov@lukoil.com \\ 1 Tyumen Industrial University, \\ 70, Melnikayte street, Tyumen, 625000, Russia. \\ 2 «KogalymNIPIneft» (Tyumen), branch of LLC «LUKOIL-Engineering», \\ 41, Respubliki street, Tyumen, 625000, Russia. \\ 3 LLC «LUKOIL-West Siberia», \\ 20, Pribaltiyskaya street, Kogalym, 628486, Russia.
}

Research relevance. Middle Jurassic reservoirs are oil-bearing in 21 fields from total of 26 being produced by JSC LUKOIL-West Siberia in the Shaimsky oil-and-gas area, they contain $56 \%$ of recoverable oil reserves. Middle Jurassic reservoirs have complex geological structure and are characterized by cross-sectional heterogeneity and lateral discontinuity, have low reservoir properties in general. Oil reserves in the reservoirs of Tyumen geological interval are classified as hard-to-recover based on the fields stratigraphy. Cumulative oil production from these reservoirs reached only 8,6\% from the total initial recoverable reserves as of 01.01.2021. Production rate is $0,4 \%$ of the initial recoverable reserves per year. Research of the development of Tyumen geological interval reservoirs is a relevant exercise.

The purpose of the research is to reveal key geological and geophysical features of the development of Tyumen geological interval reservoirs in order to identify the best methods and technologies to increase efficiency of their development.

Subject: reservoirs of Tyumen geological interval in the Shaimsky area.

Methods: literature research, analysis of the available experience of the development of Tyumen geological interval reservoirs based on the example of three fields of JSC LUKOIL-West Siberia.

Executive summary. The paper analyzes and summarizes the specificities of geological structure, experience of the development of Tyumen geological interval reservoirs and the main methods of production enhancement and improvement of field development. Significant distinctions in the efficiency of field development are revealed based on the results of the carried-out analysis of geological and geophysical characteristics of the development of Tyumen geological interval reservoirs. According to the results of interpretation of the hydrodynamic researches conducted on considered fields, in two of them reservoirs with dual flow conditions (through both matrix and fractures) have been identified, which could have essential impact on the efficiency of development of these specified fields. Low performance of the development of Tyumen geological interval reservoirs is often caused by the use of uniform grid of the production wells, chosen due to insufficient knowledge of fields geological structure. The key issue is the evaluation of the recoverable reserves and the possibility to forecast production parameters using corresponding characteristics of oil drainage in accordance with the type of produced reservoir.

\section{Key words:}

Tyumen geological interval, low-productive reservoirs, dual flow conditions, matrix and fractured reservoirs, features of development, hydrodynamic researches, water injection.

\section{REFERENCES}

1. Shpurov I.V., Pisarnitskiy A.D., Purtova I.P., Varichenko A.I. Trudnoizvlekaemye zapasy nefti Rossiyskoy Federatsii. Struktura, sostoyanie, perspektivy osvoeniya: monografiya [Hard-to-recover oil reserves of the Russian Federation. Structure, state, development prospects: monograph]. Tyumen, ZapSibNIIGG, 2012. 256 p.

2. Bembel S.R. Analysis of U2 horizon geological structure in Western Siberia based on seismic data. Norwegian Journal of development of the international science, 2019, no. 36, pp. 10-13. In Rus.

3. Yudchits V.V., Litovar R.E., Sentsov A.Yu., Druchin V.S., Yunusov R.R., Nazarov M.V. Improvement of system of development of the Symoryakhsky field with use of complex design wells. Geology, geophysics and development of oil and gas fields, 2020 , vol. 345 , no. 9, pp. 87-92. In Rus.
4. Shpurov I.V., Zakharenko V.A., Fursov A.Ya. Differentiated analysis of Jurassic oil reserves involvement degree and its depletion within West Siberian basin. Nedropolzovanie XXI vek, 2015, vol. 51, no. 1, pp. 12-19. In Rus.

5. Qi-guo Liu, You-jie Xu, Xian Peng, Yicheng Liu, Shengzhi Qi. Pressure transient analysis for multi-wing fractured wells in dualpermeability hydrocarbon reservoirs. Journal of Petroleum Science and Engineering, 2019, vol. 180, pp. 278-288.

6. Grachev S.I., Chernyaev A.V., Shpurov I.V. Improvement of Jurassic deposits development. Izvestiya visshikh uchebnykh zavedeniy. Neft i gaz, 2012, no. 4, pp. 53-57. In Rus.

7. Arzhilovskaya N.G., Baymukhametov D.S., Druchin V.S., Khlyzov P.V., Mazitov M.R. Osobennosti geologicheskogo stroeniya i kontseptualnye geologicheskie modeli produktivnykh plastov Kochevskogo mestorozhdeniya, zapasy kotorykh otseneny $\mathrm{k}$ kategorii trudnoizvlekaemykh [Geological structure and concep- 
tual geological models of productive strata of Kochevskoye field with hard-to-recover oil reserves]. Aktualnye problemy neftegazovoy otrasli. Sbornik dokladov nauchno-prakticheskikh konferentsiy zhurnala "Neftyanoe khozyaystvo». Moscow, 2019. pp. $108-117$.

8. Pouladi B., Sharifi M., Akbari M.R., Hosseini Nasab S.M. A new numerical well testing approach: application to characterization of complex fault structures. Petroleum, 2019. vol. 5, Iss. 3, pp. 295-302.

9. Qiguo Liu, Heng Lu, Longxin Li, Aiting Mu. Study on characteristics of welltest type curves for composite reservoir with sealing faults. Petroleum, 2018, vol. 4, Iss. 3, pp. 309-317.

10. Warren J.E., Root P.J. The behavior of naturally fractured reservoirs. Society of Petroleum Engineers Journal, 1963, vol. September, pp. 245-255.

11. Kazemi H., Merrill L.S., Porterfield K.L., Zeman P.R. Numerical Simulation of Water-Oil Flow in Naturally Fractured Reservoirs. Society of Petroleum Engineers Journal, 1976, vol. December pp. 317-326.

12. Grachev S.I., Korotenko V.A., Kushakova N.P. Study on influence of two-phase filtration transformation on formation of zones of undeveloped oil reserves. Journal of Mining Institute, 2020, vol. 241, pp. 68-82.

13. Nie Ren-Shi, Meng Ying-Feng, Jia, Yong-Lu, Zhang Fu-Xiang, Yang Xiang-Tong, Niu Xin-Nian. Dual porosity and dual permeability modeling of horizontal well in naturally fractured reservoir. Transport in Porous Media, 2012, vol. 92, pp. 213-235.

14. Uleberg K., Kleppe J. Dual porosity, dual permeability formulation for fractured reservoir simulation. Norwegian University of Science and Technology, Trondheim RUTH Seminar, Stavanger, 1996.

15. Afanasev A.V., Gorbunov A.T., Shustef I.N. Zavodnenie neftyanykh mestorozhdeniy pri vysokikh davleniyakh nagnetaniya
[Waterflooding of oil fields at high injection pressures]. Moscow, Nedra Publ., 1975. 215 p.

16. Medvedskii R.I. Kontseptsiya struynogo vytesneniya nefti vodoy [Concept of oil displacement by water jet]. Vestnik Udmurtskogo universiteta, 2002, no. 9, pp. 121-129.

17. Medvedskii R.I., Sevastyanov A.A. Sopostavlenie metodov prognozirovaniya izvlecheniya zapasov nefti $\mathrm{v}$ sloistykh plastakh [Comparison of oil recovery prediction methods from interbedded formations]. Izvestiya vysshikh uchebnykh zavedeniy. Neft i gaz, 1998, no. 4, pp. 42-47.

18. Medvedskii R.I., Sevastyanov A.A. Ispolzovanie obobschennoy kharakteristiki vytesneniya pri analize razrabotki i prognozirovanii vyrabotki zapasov [Analysis of development scheme and prediction of reserves recovery using generalized fluids displacement parameters]. Puti realizatsii neftegazovogo potentsiala KhMAO. Shestaya nauchno-prakticheskaya konferentsiya [How to unlock oil \& gas potential of Khanty-Mansyiskiy region. $6^{\text {th }}$ scientificengineering conference]. Khanty-Mansiysk, 2003. pp. 371-384

19. Stenkin A.V., Kotenov Yu.A., Sultanov S.K., Umetbaev V.G. Methodical substantiation of increasing production of oil reserves on the fields complicated by tectonic disturbances. Bulletin of the Tomsk Polytechnic University. Geo Assets Engineering, 2019, vol. 330, no. 1, pp. 214-223. In Rus.

20. Bembel S.R., Avershin R.V., Bembel R.M., Kislukhin V.I. Geological model and optimal well placement substantiation at the western part Tyumen suite layers of Khanty-Mansiysk Autonomous Okrug - Ugra. Izvestiya vysshikh uchebnykh zavedeniy. Neft i gaz, 2020, no. 6, pp. 8-24. In Rus.

Received: 13 October 2021.

\section{Information about the authors}

Sergey I. Grachev, Dr. Sc., professor, head of Oil and Gas Fields Development Department, Tyumen Industrial University.

Vitaly V. Yudchits, head of V.N. Vinogradov Field Development Design and Monitoring Division, «KogalymNIPIneft» (Tyumen), branch of LLC «LUKOIL-Engineering».

Vitaly S. Druchin, Cand. Sc., deputy director for Research in the field of Geology «KogalymNIPIneft» (Tyumen), branch of LLC «LUKOIL-Engineering».

Radmir R. Yunusov, head of Oil and Gas Fields Development Control and Analysis Division LLC «LUKOIL-West Siberia». 